\title{
Lesion of the Cerebellar Noradrenergic Innervation Enhances the Harmaline-Induced Tremor in Rats
}

\author{
Waclaw Kolasiewicz • Katarzyna Kuter • \\ Przemysław Nowak • Agnieszka Pastuszka • \\ Krystyna Ossowska
}

Published online: 29 January 2011

(C) The Author(s) 2011. This article is published with open access at Springerlink.com

\begin{abstract}
Abnormal synchronous activation of the glutamatergic olivo-cerebellar pathway has been suggested to be crucial for the harmaline-induced tremor. The cerebellum receives two catecholaminergic pathways: the dopaminergic pathway arising from the ventral tegmental area/ substantia nigra pars compacta, and the noradrenergic one from the locus coeruleus. The aim of the present study was to examine a contribution of the cerebellar catecholaminergic innervations to the harmaline-induced tremor in rats. Rats were injected bilaterally into the cerebellar vermis with 6-hydroxydopamine (6-OHDA; $8 \mu \mathrm{g} / 0.5 \mu \mathrm{l})$ either alone or this treatment was preceded ( 30 min earlier) by desipramine (15 mg/kg ip). Harmaline was administered to animals in doses of 7.5 or $15 \mathrm{mg} / \mathrm{kg}$ ip. Tremor of forelimbs was measured as a number of episodes during a 90-min
\end{abstract}

The authors state that there is no conflict of interest which might bias the present study.

W. Kolasiewicz $\cdot$ K. Kuter $\cdot$ K. Ossowska $(\bowtie)$

Department of Neuro-Psychopharmacology,

Institute of Pharmacology, Polish Academy of Sciences,

12 Smętna St,

31-343, Kraków, Poland

e-mail: ossowska@if-pan.krakow.pl

P. Nowak

Department of Pharmacology,

Medical University of Silesia,

19 H. Jordana St,

41-808, Zabrze, Poland

\section{A. Pastuszka}

Department of Descriptive and Topographic Anatomy,

Medical University of Silesia,

19 H. Jordana St,

41-808, Zabrze, Poland observation. Rats were killed by decapitation 30 or $120 \mathrm{~min}$ after harmaline treatment. The levels of dopamine, noradrenaline, serotonin, and their metabolites were measured by HPLC in the cerebellum, substantia nigra, caudateputamen, and frontal cortex. 6-OHDA injected alone enhanced the harmaline-induced tremor. Furthermore, it decreased the noradrenaline level by ca. $40-80 \%$ in the cerebellum and increased the levels of serotonin and 5HIAA in the caudate-putamen and frontal cortex in untreated and/or harmaline-treated animals. When 6OHDA treatment was preceded by desipramine, it decreased dopaminergic transmission in some regions of the cerebellum while inducing its compensatory activation in others. The latter lesion did not markedly influence the tremor induced by harmaline. The present study indicates that noradrenergic innervation of the cerebellum interacts with cerebral serotonergic systems and plays an inhibitory role in the harmaline-induced tremor.

Keywords Harmaline - Tremor - Cerebellum .

Noradrenaline $\cdot$ Dopamine $\cdot$ Serotonin $\cdot$ Rat

\section{Introduction}

The cerebellum is generally accepted to be involved in the control and integration of motor processes as well as of cognitive functions. Several studies have suggested an important role of this structure in pathological processes underlying different forms of tremor, schizophrenia, attention deficit, and Parkinson's disease. Abnormal activation of climbing glutamatergic fibers arising from the inferior olive, which induces synchronous firing of Purkinje cells of the cerebellar cortex has been assumed 
to be a "pacemaker" responsible for development of essential tremor [1]. Moreover, recent studies have suggested some contribution of the cerebellum and its efferent connections with the ventrolateral thalamus to the tremor accompanying Parkinson's disease [2-9]. The cerebellar cortex receives catecholaminergic innervations that include a small dopaminergic pathway arising from the ventral tegmental area/substantia nigra pars compacta, and a heavy noradrenergic projection from the locus coeruleus [10-14]. These regions are destroyed in the course of Parkinson's disease [15]; however, a contribution of losses of dopaminergic and/or noradrenergic cerebellar terminals to Parkinsonian tremor has not been evaluated, so far. In contrast, an important role of the locus coeruleus and cerebellum to the essential tremor has been strongly suggested [16, 17].

Harmaline, a derivative of $\beta$-carboline is a well-known tremorgenic compound which has been suggested to model essential tremor in animals [18]. Harmaline induces the action and postural tremor in several animal species which is manifested by the tremor of fore and hind limbs, head tremor or generalized tremor of the whole body [18-21]. Oscillation frequency in this tremor decreases with increasing weight of an animal and is equal to $11-14 \mathrm{~Hz}$ in mice, $10-12 \mathrm{~Hz}$ in rats, and $8-10 \mathrm{~Hz}$ in monkeys [18]. Although a synchronous activation of the olivo-cerebellar pathway and release of glutamate in the cerebellum which acts at NMDA and AMPA receptors has been suggested to be a primary cause of the harmaline-induced tremor [18, 22, 23], the mechanisms underlying this symptom seem to be complex and may involve also noradrenergic, serotonergic, dopaminergic, and GABA-ergic systems [23-26], as well as some distant brain structures, e.g., reticular formation, caudate-putamen, frontal cortex, and others [27-29]. The latter assumption is based on the fact that a systemic harmaline administration in tremorgenic doses induces metabolic and neuronal activation in the above structures [27-29]. Moreover, since harmaline has been found to modulate postural tremor induced by a lesion of the substantia nigra in monkeys [30], some interrelationship between neuronal alterations triggered by harmaline and those underlying tremor induced by degeneration of dopaminergic neurons may be suggested.

The aim of the present study was to examine an influence of lesions of the cerebellar catecholaminergic innervations on the harmaline-induced tremor and biochemical alterations in this structure, as well as in the substantia nigra, caudate-putamen and frontal cortex in rats. To this aim, 6-hydroxydopamine (6-OHDA) was administered directly into the cerebellum alone or in combination with desipramine, in order to simultaneously produce a lesion of dopaminergic and noradrenergic terminals or only dopaminergic innervation, respectively.

\section{Materials and Methods}

The experiments were carried out in compliance with the Animal Protection Bill of August 21, 1997; (published in Journal of Laws no. 111/1997 item 724), and according to the NIH Guide for the Care and Use of Laboratory Animals. They received also an approval of Local Ethical Committee. All efforts were made to minimize the number and suffering of animals used.

Male Wistar rats weighing $220-250$ or $350-380 \mathrm{~g}$ (assigned for operations) prior to experiments were kept on a light/dark cycle $(12 / 12 \mathrm{~h}$; the light on from 7 am to $7 \mathrm{pm}$ ) with free access to food and water.

\section{Operations}

Under the pentobarbital anesthesia (Vetbutal, Biowet, Poland; $25 \mathrm{mg} / \mathrm{kg}$, i.p.) the animals were fixed into the stereotaxic instrument (Stoelting, USA) and injected with 6OHDA into the cerebellum. Tips of injection cannulae were placed at the border between lobules 9 and 10 of the cerebellar vermis (AP: $-13.2 \mathrm{~mm}, \mathrm{~L}: \pm 1.3, \mathrm{~V}: 6.6 \mathrm{~mm}$, in reference to Bregma, according to Paxinos and Watson's atlas [31]). 6-OHDA HBr (Sigma, Aldrich) was dissolved in a $0.05 \%$ ascorbic acid and injected bilaterally into the cerebellum in a dose of $8 \mu \mathrm{g} / 0.5 \mu \mathrm{l} /$ side using a $1 \mu \mathrm{l}$ Hamilton syringe with a speed $0.1 \mu 1 / 30 \mathrm{~s}$. The injection cannulae were left in place for $60 \mathrm{~s}$ in order to enable absorption of the solution. Control (sham-operated) rats received $0.5 \mu \mathrm{l}$ of ascorbic acid solution bilaterally into the aforementioned region of the cerebellum. In order to spare noradrenergic terminals, a group of rats was injected with desipramine (Sigma-Aldrich, Germany) in a dose of $15 \mathrm{mg} /$ $2 \mathrm{ml} / \mathrm{kg}$ ip $30 \mathrm{~min}$ before intrastructural injections. In order to avoid infections, the rats received an antibiotic (Lincospectin, Pharmacia, Belgium, $0.1 \mathrm{ml} / \mathrm{kg}$ ) $24 \mathrm{~h}$ before the operation, on the day of operation and $24 \mathrm{~h}$ afterwards.

\section{Behavioral Observations}

Rats were weighed on the day of operation, as well as 1,3 , 7 , and 9 days afterwards. The open field test was carried out on the eighth day after the operation. The field was a square $(60 \times 70 \mathrm{~cm})$ surrounded by a wall of $30 \mathrm{~cm}$ high having 10 holes (two and three in each shorter and longer side, respectively) and was illuminated by white light emitted by a bulb located above its center. Rats were placed individually at the center of the field and their behavior was evaluated during a 10-min session. Time spent for locomotor activity or grooming, and the number of rearings and peepings into holes were measured.

Harmaline (Sigma, Germany) was dissolved in sterile water and injected in a dose of $7.5 \mathrm{mg} / \mathrm{kg}$ ip on the ninth 
day after the operation. Rats were placed individually in a Plexiglas cage $(40 \times 40 \times 25 \mathrm{~cm})$ and video recordings of their behavior were taken during $90 \mathrm{~min}$ after harmaline injections. This behavior was analyzed afterwards and quantified according to the procedures described earlier [21]. Briefly, the tremor of forelimbs was measured by a number of episodes, while hind leg abduction and balance disturbances were scored semi-quantitatively according to the arbitrarily accepted three-point scales. After finishing the behavioral experiments, the rats were killed by decapitation and the localization of their cannula tips were examined on histological slices stained with the Nissl method (Fig. 1).

Biochemical HPLC Analyses of Monoamines and Their Metabolites (According to Modified Methods [32, 33])

Naïve or operated rats (on the ninth day after the operation) were treated with harmaline in doses of 7.5 or $15 \mathrm{mg} / \mathrm{kg}$ ip and killed by decapitation 30 or 120 min after injections. Their brains were rapidly removed and dissected on a

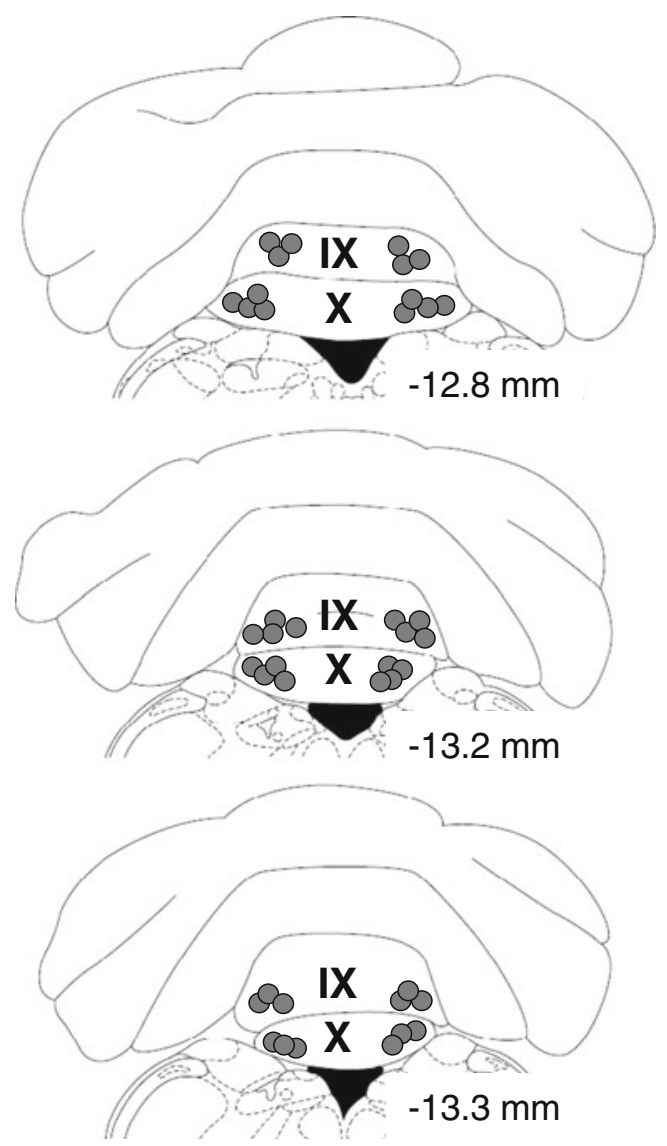

Fig. 1 Histologically confirmed localization of cannula tips (filled circles) shown in frontal sections of the rat cerebellum in reference to bregma according to Paxinos and Watson [31]. Roman numbers indicate respective lobules chilled plate using curved micro-forceps. First, the substantia nigra was separated from the mesencephalon at the level of oculomotor nerve root and excised. Then, the frontal cortex was detached by a vertical cut carried out at the level ca. $\mathrm{AP}=+4.5 \mathrm{~mm}$ with reference to the bregma (according to Paxinos and Watson [31]). Afterwards, the whole caudate-putamen was exposed and taken out. Finally, the cerebellar lobules $1-3,4-7$, and 8-10 (containing both corresponding vermis and hemispheres) were excised by cuts carried out along respective fissures. The tissues were immediately frozen and stored at $-80^{\circ} \mathrm{C}$ until further procedures were applied.

Levels of dopamine and its metabolites-3,4-dihydroxyphenylacetic acid (DOPAC), 3-methoxytyramine (3-MT), homovanillic acid (HVA), serotonin (5-HT), its metabolite5-hydroxyindoleacetic acid (5-HIAA), noradrenaline, and in some cases 3-methoxy-4-hydroxy-phenylethyleneglycol (MOPEG) were assessed using an HPLC method with electrochemical detection.

Tissue samples were homogenized in $0.1 \mathrm{M}$ perchloric acid containing $0.05 \mathrm{mM}$ ascorbic acid. Tissue homogenates were then centrifuged $\left(10,000 \times g, 15 \mathrm{~min}, 4^{\circ} \mathrm{C}\right)$, filtered through $0.2 \mu \mathrm{m}$ cellulose membrane, centrifuged again $\left(4,000 \times \mathrm{g}, 3 \mathrm{~min}, 4^{\circ} \mathrm{C}\right)$ and injected into the system that consisted of thermally controlled ASI-100 autosampler $\left(4^{\circ} \mathrm{C}\right)$, P680 isocratic pump with degasser (Dionex, Germany), column [Hypersil, $150 \times 3.0 \mathrm{~mm}, 3 \mu \mathrm{m}$ (for the caudate-putamen and frontal cortex) or $4.6 \mathrm{~mm}, 3 \mu \mathrm{m}$ (for the cerebellar lobules and substantia nigra), Thermo Scientific, UK], TCC-100 thermally controlled column compartment $\left[32^{\circ} \mathrm{C}\right.$ (for the caudate-putamen and frontal cortex) or $22^{\circ} \mathrm{C}$ (for the cerebellar lobules and substantia nigra), Dionex, Germany], and electrochemical detector analytic cell 5010 Coulochem III (ESA, Inc. USA). The mobile phase for the caudate-putamen and frontal cortex was composed of $50 \mathrm{mM} \mathrm{NaH} \mathrm{PO}_{4} \times 2 \mathrm{H}_{2} \mathrm{O}, 40 \mathrm{mM}$ citric acid, $0.25 \mathrm{mM}$ 1-octanesulfonic acid sodium salt, $0.25 \mathrm{mM}$ EDTA, $1.3 \%$ acetonitrile, and $2.4 \%$ methanol. The mobile phase for the cerebellar lobules and substantia nigra consisted of $75 \mathrm{mM} \mathrm{NaH} \mathrm{PO}_{4} \times 2 \mathrm{H}_{2} \mathrm{O}, 1.7 \mathrm{mM} \mathrm{1-}$ octanosulfonic acid, $5 \mu \mathrm{M}$ EDTA, $100 \mu \mathrm{l}$ of triethylamine/ $11,9.5 \%$ acetonitrile, and phosphoric acid $(\mathrm{pH}=3)$. The flow rate was $0.7 \mathrm{ml} / \mathrm{min}$. The applied potential was $\mathrm{E} 1=$ 175 or $-50 \mathrm{mV}$ and $\mathrm{E} 2=+350 \mathrm{mV}$.

The data were quantified using the area under the peaks and external standards, using Chromeleon software (Dionex, Germany). The turnover of amines was calculated as metabolite to neurotransmitter ratio.

\section{Statistics}

The data related to tremor and weight was analyzed by ANOVA for repeated measures and least significant 
difference (LSD) post hoc test. The biochemical data were analyzed either by two-way ANOVA and LSD post hoc test (naïve rats) or one-way ANOVA and LSD post hoc test (operated rats). All statistical calculations were done using STATISTICA 7.0 Software (Statsoft, Inc. USA).

\section{Results}

\section{Behavioral Observations}

\section{Spontaneous Behavior}

During the first $24 \mathrm{~h}$ after the operation all animals (shamoperated and lesioned) lost their weight to a similar degree $(>20 \mathrm{~g})$. During the following days, however, the weight of rats which received 6-OHDA $(8 \mu \mathrm{g} / 0.5 \mu \mathrm{l})$ with or without desipramine $(15 \mathrm{mg} / \mathrm{kg}$ ip) further decreased while that of sham-operated animals returned to the almost normal level on the ninth day after the operation (Fig. 2).

Analysis of rats' behavior in the open field test carried out on the eighth day after operation did not reveal any differences between sham-operated and lesioned rats which received 6OHDA with or without desipramine with respect to the time spent for locomotor activity, grooming, the number of rearings and peepings into holes (data not shown).

\section{Harmaline-Induced Behavior}

Preliminary observation of behavior of naïve rats injected with harmaline indicated that similar to our previous study [21] the lower dose of this compound $(7.5 \mathrm{mg} / \mathrm{kg}$ ip) induced intensive tremor of the forelimbs and the whole body, as well as balance disturbances, hind leg abduction, and an increase in locomotor activity which lasted longer than $90 \mathrm{~min}$. The tremor induced by the higher dose

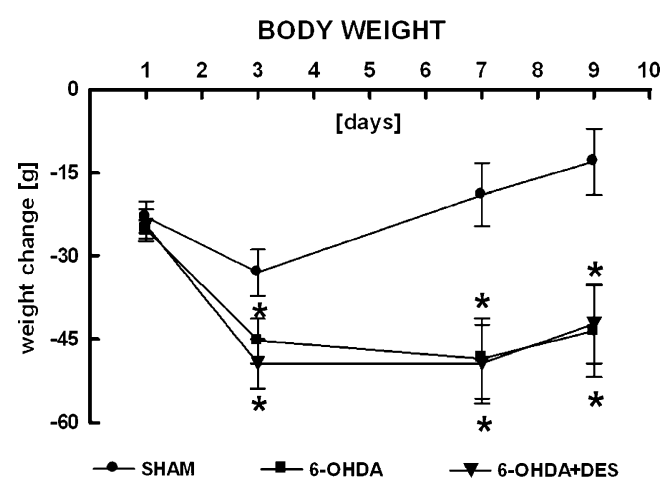

Fig. 2 Loss of body weight of rats with lesions of catecholaminergic cerebellar innervations. The results are shown as the mean \pm SEM. Abscissa days after the operation. The number of animals $n=4-7$ per group. 6-OHDA 6-hydroxydopamine, DES desipramine. ANOVA for repeated measures and LSD post hoc test, $* p<0.05$ vs. sham
$(15 \mathrm{mg} / \mathrm{kg}$ ip) was ca. $70 \%$ more intensive than that of the lower one and balance disturbances were so strong that animals fell down during any attempt to move which precluded observation and quantification of forelimb tremor. Therefore, for further examination of an influence of cerebellar lesions on the latter symptom, the lower dose $(7.5 \mathrm{mg} / \mathrm{kg}$ ip) of harmaline was chosen.

Rats lesioned with 6-OHDA (without desipramine) exhibited a marked and statistically significant increase in the harmaline-induced tremor of forelimbs. That effect was the strongest between 30 and $60 \mathrm{~min}$ after administration of this drug (Fig. 3). In contrast, the lesion induced by 6OHDA injected together with desipramine $(15 \mathrm{mg} / \mathrm{kg}$ ip $)$ did not influence forelimb tremor induced by harmaline (Fig. 3). Moreover, both types of 6-OHDA-induced lesions did not alter balance disturbances and hind leg abduction evoked by harmaline (data not shown).

An Influence of Harmaline on Dopamine, Noradrenaline, Serotonin, and Their Metabolites in Brain Structures

\section{Dopamine and Metabolites}

Caudate-Putamen, Substantia Nigra, Frontal Cortex Harmaline administered in naïve rats in a dose of $7.5 \mathrm{mg} / \mathrm{kg}$ ip did not significantly influence dopamine levels in the caudate-putamen and substantia nigra, but decreased it in the frontal cortex $30 \mathrm{~min}$ after the administration (Fig. 4). Harmaline in a dose of $15 \mathrm{mg} / \mathrm{kg}$ increased the level of dopamine in the caudate-putamen and reduced it in the substantia nigra 30 and 120 after administration, respectively. In the frontal cortex, the level of this neurotransmitter was not lowered significantly by the latter dose of

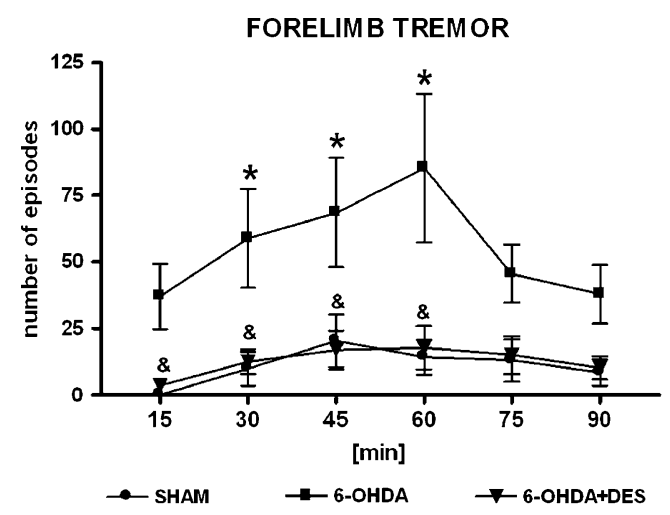

Fig. 3 An influence of lesions of catecholaminergic cerebellar innervations on the harmaline-induced $(7.5 \mathrm{mg} / \mathrm{kg} \mathrm{ip})$ tremor of forelimbs of rats. Abscissa time after harmaline administration. The results are shown as the mean \pm SEM. The number of animals $n=4-7$ per group. 6-OHDA 6-hydroxydopamine, DES desipramine. ANOVA for repeated measures and LSD post hoc test, ${ }^{*} p<0.05$ vs. SHAM, ${ }^{\star} p$ $<0.05$ vs. $6-\mathrm{OHDA}$ 
$30 \mathrm{~min}$
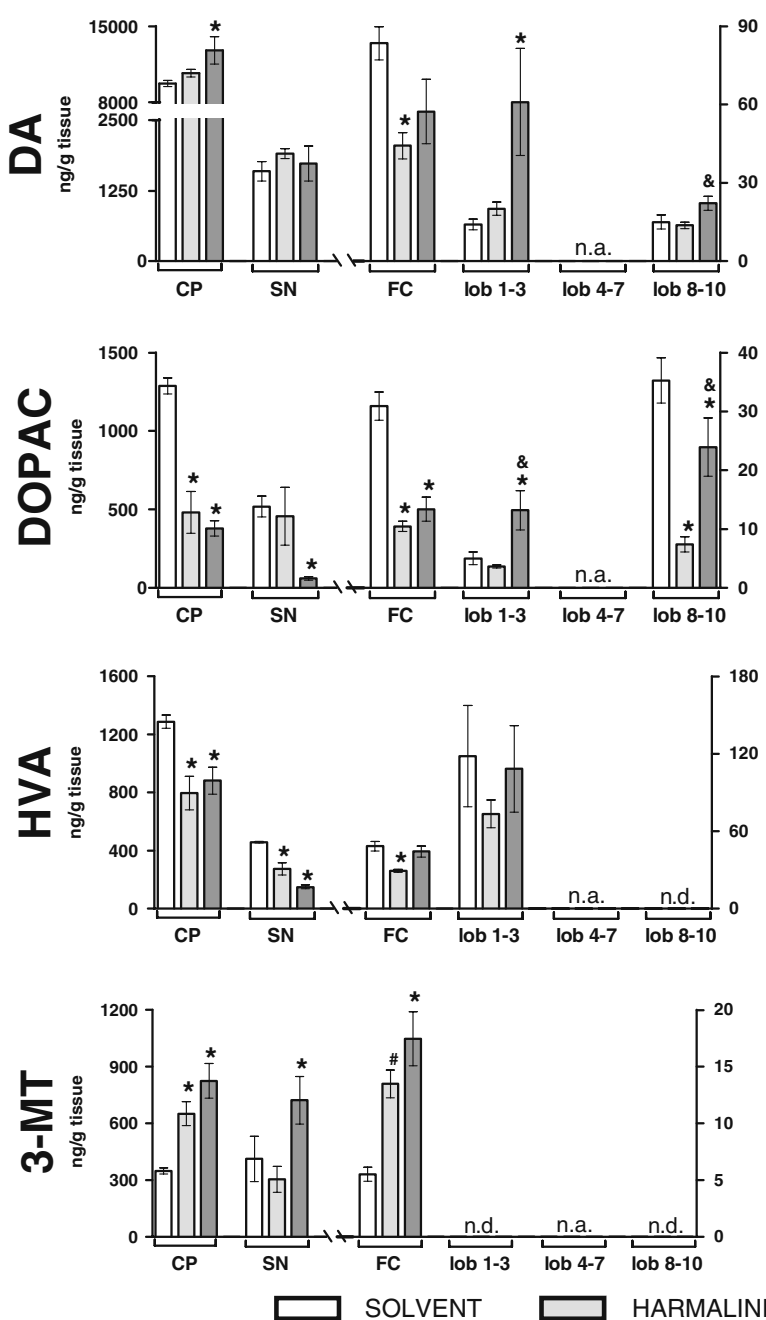

$120 \mathrm{~min}$
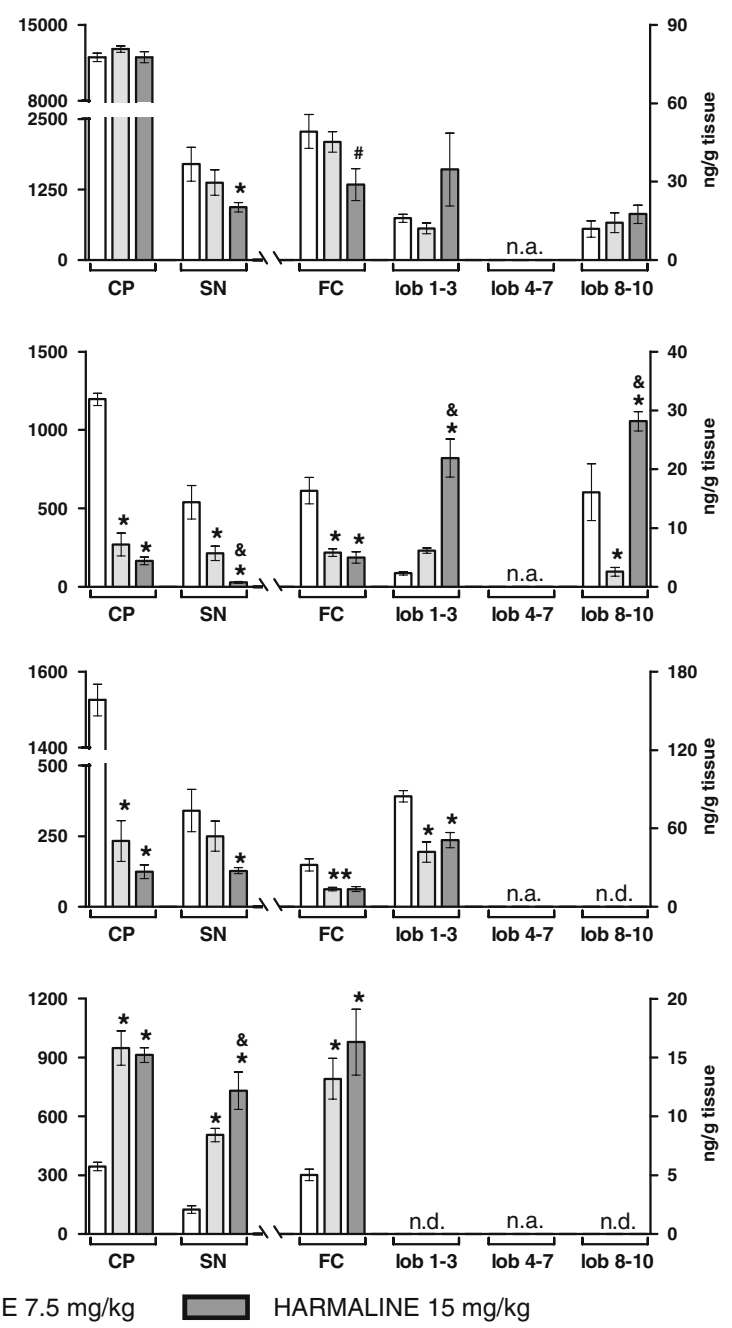

Fig. 4 The effect of harmaline $(7.5$ and $15 \mathrm{mg} / \mathrm{kg})$ on the levels of dopamine (DA) and its metabolites: DOPAC, HVA, and 3-MT in different brain structures. Rats were killed 30 or $120 \mathrm{~min}$ after harmaline administration. $C P$ caudate-putamen, $S N$ substantia nigra, FC frontal cortex, lob 1-3 lobules 1-3, lob 4-7 lobules 4-7, lob 8-10

harmaline, but a trend $(0.05<p<0.1)$ in this direction was observed $120 \mathrm{~min}$ after the injection (Fig. 4).

Harmaline administered in doses of 7.5 and $15 \mathrm{mg} / \mathrm{kg}$ profoundly decreased the levels of DOPAC, HVA, as well as DOPAC/dopamine ratios in the caudate-putamen, substantia nigra, and frontal cortex (Fig. 4, Table 1). HVA/dopamine ratios were additionally diminished in the caudate-putamen, substantia nigra (30 and $120 \mathrm{~min}$ ) after both aforementioned doses and in the frontal cortex after the lower dose of this drug $120 \mathrm{~min}$ after injection lobules $8-10$ of the cerebellum, n.a. not analyzed, n.d. not detected. The number of animals $n=6-8$ per group. The results are shown in nanogram per gram tissue (mean \pm SEM). Two-way ANOVA and LSD post hoc test. ${ }^{*} p<0.05$ vs. solvent, ${ }^{\&} p<0.05$ vs. lower dose of harmaline, ${ }^{\#} 0.05<p<0.1$ vs. solvent
(Table 1). In contrast, the higher dose of harmaline significantly elevated the HVA/dopamine ratio in the frontal cortex, but only $30 \mathrm{~min}$ after administration (Table 1).

Harmaline administered in both doses increased 3-MT levels and 3-MT/dopamine ratios in the caudate-putamen, substantia nigra, and frontal cortex (Fig. 4, Table 1).

Cerebellum Harmaline administered in a lower dose $(7.5 \mathrm{mg} / \mathrm{kg})$ did not influence the level of dopamine in the 
Table 1 An influence of harmaline $(7.5$ and $15 \mathrm{mg} / \mathrm{kg}$ ) on metabolites/monoamines ratios in different brains structures in naïve rats 30 or $120 \mathrm{~min}$ after injections

\begin{tabular}{|c|c|c|c|c|c|c|c|c|c|c|c|c|}
\hline & \multicolumn{6}{|l|}{$30 \mathrm{~min}$} & \multicolumn{6}{|c|}{$120 \mathrm{~min}$} \\
\hline & \multicolumn{2}{|l|}{ Solvent } & \multicolumn{2}{|c|}{ Harmaline 7.5} & \multicolumn{2}{|c|}{ Harmaline 15} & \multicolumn{2}{|l|}{ Solvent } & \multicolumn{2}{|c|}{ Harmaline 7.5} & \multicolumn{2}{|c|}{ Harmaline 15} \\
\hline & Mean & SEM & Mean & SEM & Mean & SEM & Mean & SEM & Mean & SEM & Mean & SEM \\
\hline & \multicolumn{12}{|c|}{ DOPAC/DA } \\
\hline $\mathrm{CP}$ & 0.1329 & 0.0055 & $0.0457^{*}$ & 0.0128 & $0.0301 *$ & 0.0033 & 0.0998 & 0.0017 & $0.0208^{*}$ & 0.0055 & $0.0135^{*}$ & 0.0015 \\
\hline SN & 0.3271 & 0.0260 & 0.2214 & 0.0783 & $0.0457 *$ & 0.0143 & 0.3418 & 0.0800 & $0.1450^{*}$ & 0.0434 & $0.0436^{*}$ & 0.0206 \\
\hline $\mathrm{FC}$ & 0.3756 & 0.0200 & $0.2453^{*}$ & 0.0234 & $0.2585^{\#}$ & 0.0246 & 0.3627 & 0.0532 & $0.1339 *$ & 0.0172 & $0.1767^{*}$ & 0.0070 \\
\hline lob $1-3$ & 0.3689 & 0.0615 & 0.1725 & 0.0180 & 0.3808 & 0.1383 & 0.1533 & 0.0240 & 0.5271 & 0.0823 & $1.7648^{*}$ & 0.7858 \\
\hline \multirow[t]{2}{*}{ lob $8-10$} & 3.0460 & 0.7738 & $0.6156^{*}$ & 0.1557 & $1.2188^{*}$ & 0.2789 & 1.2795 & 0.2575 & 0.1083 & 0.0188 & 2.1510 & 0.6204 \\
\hline & \multicolumn{12}{|c|}{ HVA/DA } \\
\hline $\mathrm{CP}$ & 0.1329 & 0.0059 & $0.0755^{*}$ & 0.0116 & $0.0703 *$ & 0.0058 & 0.1278 & 0.0048 & $0.0180^{*}$ & 0.0054 & $0.0100^{*}$ & 0.0016 \\
\hline $\mathrm{SN}$ & 0.2656 & 0.0256 & $0.1414^{*}$ & 0.0224 & $0.1045^{*}$ & 0.0161 & 0.2511 & 0.0477 & $0.1561 *$ & 0.0364 & $0.1377^{*}$ & 0.0152 \\
\hline $\mathrm{FC}$ & 0.5886 & 0.0324 & 0.6070 & 0.0499 & $0.9199 *$ & 0.1081 & 0.6905 & 0.0856 & $0.3051^{*}$ & 0.0326 & 0.5087 & 0.0368 \\
\hline lob $1-3$ & 8.6609 & 2.2380 & 3.8118 & 0.5272 & 3.3600 & 1.3956 & 5.6623 & 0.8068 & 4.1700 & 1.2064 & 4.0330 & 1.7805 \\
\hline \multirow[t]{2}{*}{ lob 8-10 } & - & - & - & - & - & - & - & - & - & - & - & - \\
\hline & \multicolumn{12}{|c|}{ 3-MT/DA } \\
\hline $\mathrm{CP}$ & 0.0363 & 0.0022 & $0.0614 *$ & 0.0063 & $0.0656^{*}$ & 0.0056 & 0.0288 & 0.0018 & $0.0747^{*}$ & 0.0071 & $0.0765^{*}$ & 0.0037 \\
\hline SN & 0.2964 & 0.1157 & 0.1670 & 0.0395 & 0.4373 & 0.0727 & 0.0813 & 0.0163 & $0.3557^{*}$ & 0.0710 & $0.7096^{*}$ & 0.1318 \\
\hline $\mathrm{FC}$ & 0.0850 & 0.0181 & $0.3268^{\#}$ & 0.0438 & $0.3819^{*}$ & 0.0714 & 0.1296 & 0.0193 & $0.3237^{*}$ & 0.0654 & $0.6405^{*}$ & 0.0856 \\
\hline lob $1-3$ & - & - & - & - & - & - & - & - & - & - & - & - \\
\hline \multirow[t]{2}{*}{ lob 8-10 } & - & - & - & - & - & - & - & - & - & - & - & - \\
\hline & \multicolumn{12}{|c|}{ 5-HIAA/5-HT } \\
\hline $\mathrm{CP}$ & 1.1462 & 0.0495 & $0.8130^{*}$ & 0.0694 & 0.9378 & 0.0469 & 1.2418 & 0.0435 & $0.5906^{*}$ & 0.0732 & $0.5635^{*}$ & 0.0320 \\
\hline SN & 0.4548 & 0.1007 & 0.4959 & 0.0581 & 0.5283 & 0.0828 & 0.8242 & 0.1078 & $0.3948^{*}$ & 0.0350 & $0.3762 *$ & 0.0520 \\
\hline $\mathrm{FC}$ & 1.6240 & 0.1261 & $0.5977^{*}$ & 0.0261 & $0.7057^{*}$ & 0.0341 & 1.5969 & 0.2575 & $0.5484^{*}$ & 0.0717 & $0.4903^{*}$ & 0.0326 \\
\hline lob $1-3$ & 3.4631 & 0.4753 & $1.2206^{*}$ & 0.0375 & $1.6151 *$ & 0.1775 & 2.4187 & 0.1319 & 1.1709 & 0.1393 & $3.0202 *$ & 1.2923 \\
\hline \multirow[t]{2}{*}{ lob $8-10$} & 2.7490 & 0.3183 & $0.5090^{*}$ & 0.0718 & $0.5731 *$ & 0.0724 & 2.8208 & 0.4875 & $0.4327^{*}$ & 0.0335 & $0.5066^{*}$ & 0.0299 \\
\hline & \multicolumn{12}{|c|}{ MOPEG/NA } \\
\hline $\mathrm{CP}$ & - & - & - & - & - & - & - & - & - & - & - & - \\
\hline SN & - & - & - & - & - & - & - & - & - & - & - & - \\
\hline $\mathrm{FC}$ & 0.0854 & 0.0232 & $0.0237^{*}$ & 0.0063 & $0.0205 *$ & 0.0060 & 0.0078 & 0.0010 & 0.0058 & 0.0010 & 0.0046 & 0.0005 \\
\hline lob $1-3$ & - & - & - & - & - & - & - & - & - & - & - & - \\
\hline lob $8-10$ & - & - & - & - & - & - & - & - & - & - & - & - \\
\hline
\end{tabular}

Two-way ANOVA and LSD post hoc test

$C P$ caudate-putamen, $F C$ frontal cortex, $S N$ substantia nigra, lob 1-3 lobules 1-3, lob 8-10 lobules 8-10 of the cerebellum ${ }^{*} p<0.05$ vs. solvent, ${ }^{\#} 0.05<p<0.1$ vs. solvent

cerebellum, but lowered DOPAC and DOPAC/dopamine ratio in lobules 8-10 (Fig. 4, Table 1). The higher dose of harmaline $(15 \mathrm{mg} / \mathrm{kg})$ decreased the level of DOPAC and DOPAC/dopamine ratio in lobules $8-10$ at $30 \mathrm{~min}$, but produced an opposite effect at $120 \mathrm{~min}$ after administration (Fig. 4, Table 1). Moreover, the level of dopamine (30 min), DOPAC (30 and $120 \mathrm{~min}$ ) and DOPAC/ dopamine ratio $(120 \mathrm{~min})$ were elevated in lobules $1-3$ after the latter dose of harmaline (Fig. 4, Table 1). HVA levels were diminished in lobules 1-3 after both the aforementioned doses of harmaline, but only 120 min after administration (Fig. 4). 3-MT was not detectable in lobules $1-3$ or in $8-10$ (Fig. 4).

Serotonin, Noradrenaline, and Their Metabolites

Caudate-Putamen, Substantia Nigra, Frontal Cortex Harmaline administered in doses of 7.5 and $15 \mathrm{mg} / \mathrm{kg}$ did not 
influence the serotonin level in the caudate-putamen and substantia nigra, but increased it in the frontal cortex. The 5-HIAA level was strongly lowered in the frontal cortex (30 min and 120 after harmaline), and in the caudateputamen and substantia nigra (120 min after harmaline; Fig. 5). 5-HIAA/serotonin ratios were decreased in all the above structures (Table 1).

The noradrenaline level was not altered by harmaline in the caudate-putamen and substantia nigra. However, this compound in the higher dose $(15 \mathrm{mg} / \mathrm{kg})$ increased the level of this neurotransmitter in the frontal cortex (Fig. 5). Moreover, both doses reduced the MOPEG/noradrenaline ratio in the latter structure (Table 1).

Cerebellum The level of serotonin was increased in the lobules $1-3$ and $8-10$ after both doses of harmaline (Fig. 5). In the lobules 8-10, the level of 5-HIAA strongly declined $30 \mathrm{~min}$ after the lower dose of harmaline; and in lobules 13 and 8-10, 120 min after both doses of this compound (Fig. 5). The 5-HIAA/serotonin ratio also decreased in the aforementioned cerebellar regions, with one exception-in lobules $1-3$, it was elevated after the higher dose of harmaline $120 \mathrm{~min}$ after administration (Table 1).
The noradrenaline level was significantly enhanced after the lower dose of harmaline $(7.5 \mathrm{mg} / \mathrm{kg})$ in lobules $8-10$ (30 min and $120 \mathrm{~min}$ after administration) and in lobules 13 (120 min after administration; Fig. 5). The higher dose of this compound increased significantly the level of this neurotransmitter only in lobules $8-10$ at $30 \mathrm{~min}$, but not at $120 \mathrm{~min}$ after administration. Moreover, this enhancement was significantly lower than that produced by the lower dose (Fig. 5). The MOPEG levels were not detected in the cerebellum (Table 1).

An Influence of Lesions of Catecholaminergic Innervations of the Cerebellum on Dopamine, Noradrenaline, Serotonin, and Their Metabolites in Brain Structures

\section{Intracerebellar Injections of 6-OHDA}

Cerebellum 6-OHDA injected in a dose of $8 \mu \mathrm{g} / 0.5 \mu \mathrm{l}$ bilaterally into the lobules 9-10 dramatically decreased the noradrenaline level (by $84 \%$ ) in lobules $8-10$ and to a lesser extent in lobules 4-7 (by 51\%) but did not significantly influence the level of this neurotransmitter in lobules 1-3

\section{$30 \mathrm{~min}$}
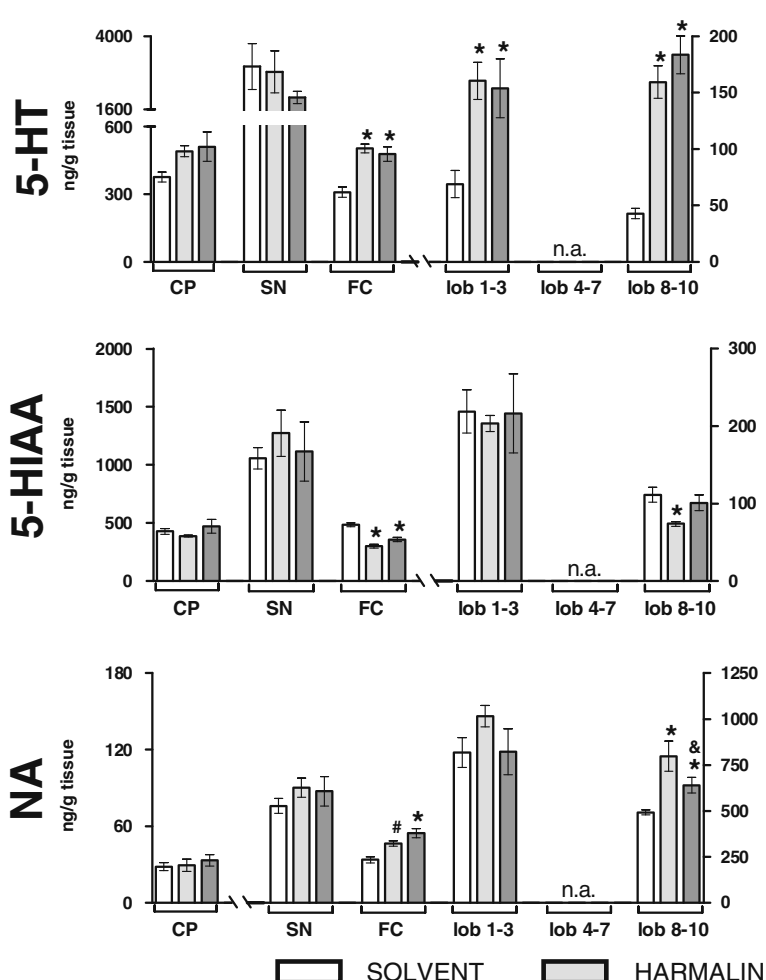

$120 \min$
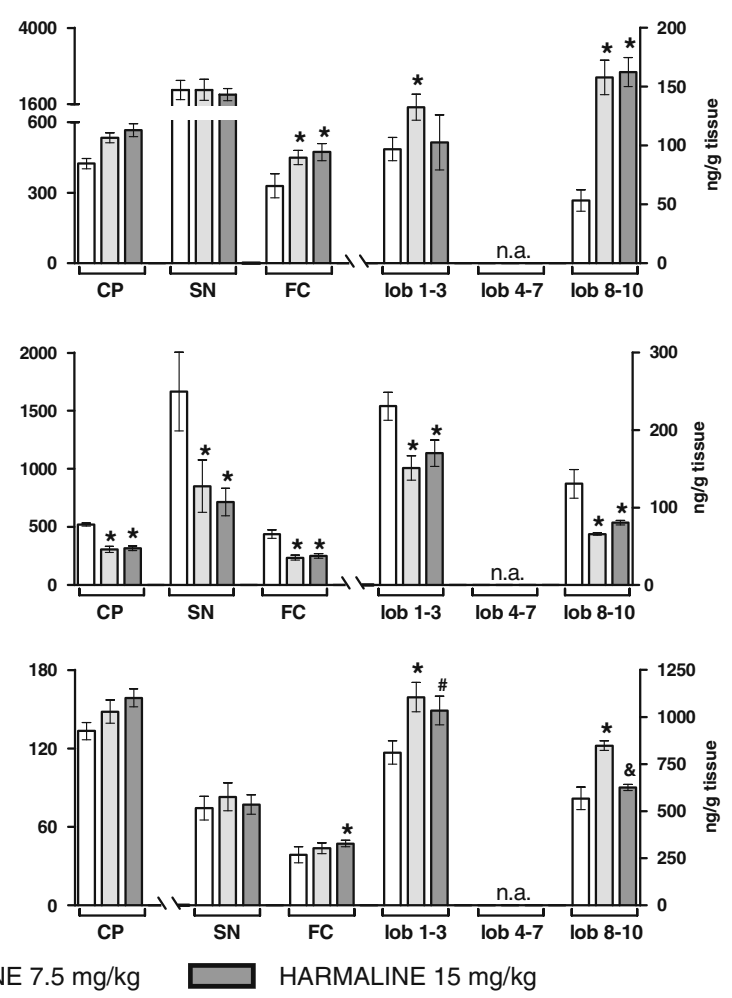

Fig. 5 The effect of harmaline ( 7.5 and $15 \mathrm{mg} / \mathrm{kg}$ ) on the levels of serotonin (5-HT), 5-HIAA and noradrenaline (NA) in different brain structures. For further explanations, see Fig. 4 
(Fig. 7). Furthermore, the above injection enhanced the dopamine level and diminished the HVA/dopamine ratio in lobules $8-10$, and tended $(0.05<p<0.1)$ to lower the 3 MT/dopamine ratio in lobules 4-7 (Fig. 6, Table 2). The 5HIAA level in lobules 4-7 was additionally decreased (Fig. 7).

Caudate-Putamen, Substantia Nigra, Frontal Cortex The levels of both serotonin and 5-HIAA in the substantia nigra and the noradrenaline level in the caudate-putamen were increased after intracerebellar 6-OHDA injections (Fig. 7).
No other alterations in neurotransmitter or their metabolites levels were observed in any structures examined (Figs. 6 and 7).

Intracerebellar Injections of 6-OHDA Together with Desipramine

Cerebellum 6-OHDA injected in a dose of $8 \mu \mathrm{g} / 0.5 \mu \mathrm{l}$ bilaterally into the lobules 9-10 $30 \mathrm{~min}$ after desipramine $(15 \mathrm{mg} / \mathrm{kg}$ ip) slightly decreased the noradrenaline level in
LESION
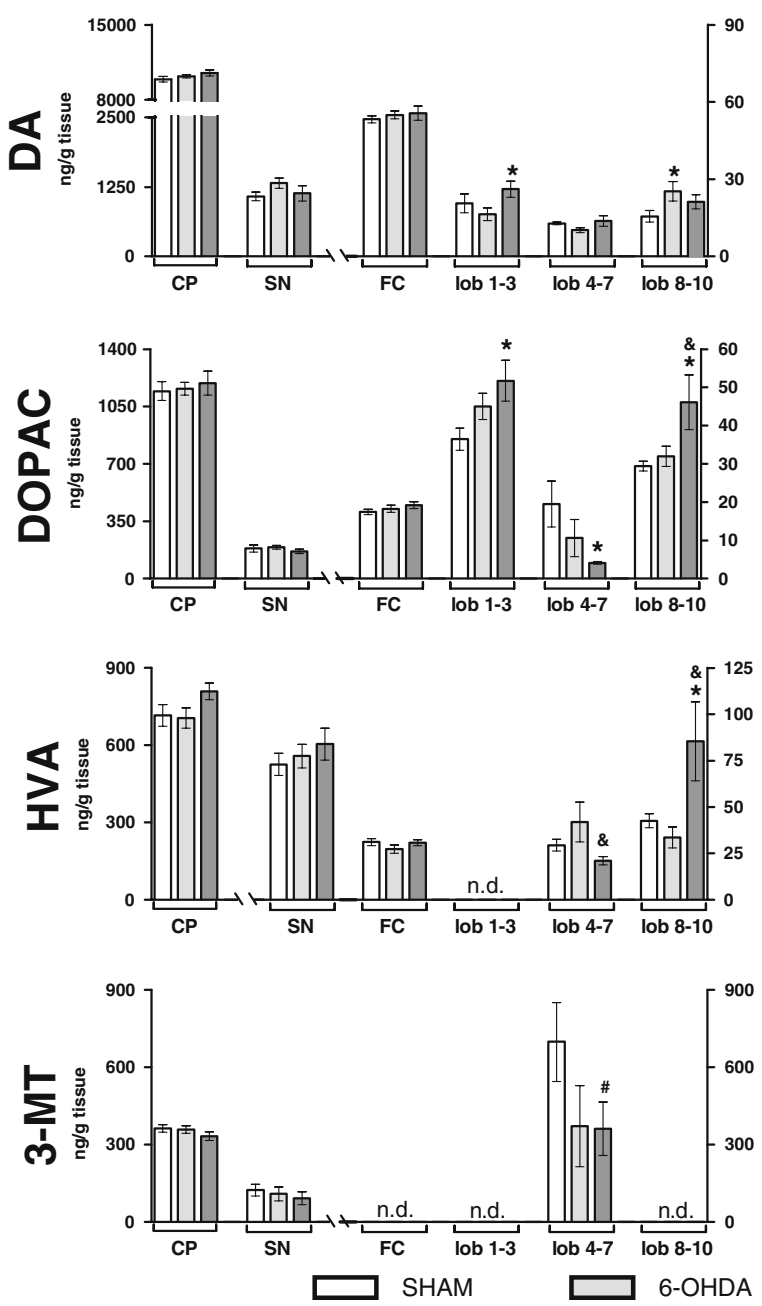

Fig. 6 An influence of lesions of cerebellar catecholaminergic innervations on the levels of dopamine (DA) and its metabolites in different brain structures in untreated (left panel) or harmaline-treated $(7.5 \mathrm{mg} / \mathrm{kg}$, right panel) rats. The animals were sacrificed on the ninth day after the operation, $120 \mathrm{~min}$ after harmaline injection. $C P$ caudate-putamen, $F C$ frontal cortex, $S N$ substantia nigra, lob 1-3

\section{LESION + HARMALINE}


lobules 1-3, lob 4-7 lobules 4-7, lob 8-10 lobules 8-10 of the cerebellum, n.d. not detected. The results are shown in nanogram per gram tissue (mean $\pm \mathrm{SEM}$ ). The number of animals $n=8-12$. One-way ANOVA and LSD post hoc test. ${ }^{*} p<0.05$ vs. sham, ${ }^{\star} p<0.05$ vs. 6 OHDA, ${ }^{\#} 0.05<p<0.1$ vs. sham 
Table 2 An influence of lesions of cerebellar catecholaminergic innervations on metabolites/monoamines ratios in different brain structures in rats untreated (left panel) or treated with harmaline $(7.5 \mathrm{mg} / \mathrm{kg}$ ip; right panel)

\begin{tabular}{|c|c|c|c|c|c|c|c|c|c|c|c|c|}
\hline & \multicolumn{6}{|l|}{ Control } & \multicolumn{6}{|c|}{ Harmaline $7.5 \mathrm{mg} / \mathrm{kg}$} \\
\hline & \multicolumn{2}{|l|}{ Sham } & \multicolumn{2}{|c|}{ 6-OHDA } & \multicolumn{2}{|c|}{ 6-OHDA+DES } & \multicolumn{2}{|l|}{ Sham } & \multicolumn{2}{|c|}{ 6-OHDA } & \multicolumn{2}{|c|}{ 6-OHDA+DES } \\
\hline & Mean & SEM & Mean & SEM & Mean & SEM & Mean & SEM & Mean & SEM & Mean & SEM \\
\hline & \multicolumn{12}{|c|}{ DOPAC/DA } \\
\hline $\mathrm{CP}$ & 100.00 & 4.04 & 98.93 & 3.65 & 98.34 & 3.75 & 100.00 & 13.44 & 103.51 & 13.27 & 107.12 & 15.46 \\
\hline SN & 100.00 & 5.26 & 88.41 & 5.48 & 90.32 & 5.67 & 100.00 & 11.04 & 84.08 & 13.47 & $137.89^{*}$ & 23.89 \\
\hline $\mathrm{FC}$ & 100.00 & 4.62 & 101.35 & 5.25 & 105.70 & 3.48 & 100.00 & 5.08 & 96.93 & 9.41 & 103.29 & 8.06 \\
\hline lob $1-3$ & 100.00 & 12.38 & 124.49 & 10.78 & 110.88 & 12.27 & 100.00 & 13.85 & 72.79 & 5.08 & 81.64 & 10.90 \\
\hline lob 4-7 & 100.00 & 32.84 & 70.23 & 32.71 & $18.19^{*}$ & 2.70 & 100.00 & 4.63 & 127.30 & 11.20 & 120.22 & 14.55 \\
\hline \multirow[t]{2}{*}{ lob 8-10 } & 100.00 & 10.89 & 79.44 & 16.21 & 105.22 & 19.89 & 100.00 & 13.48 & 105.62 & 9.41 & $192.94^{*}, \&$ & 27,90 \\
\hline & \multicolumn{12}{|c|}{ HVA/DA } \\
\hline $\mathrm{CP}$ & 100.00 & 6.21 & 96.08 & 6.29 & 106.24 & 2.43 & 100.00 & 17.97 & 111.40 & 21.25 & 120.70 & 23.37 \\
\hline $\mathrm{SN}$ & 100.00 & 7.13 & 87.22 & 5.56 & $111.06^{\&}$ & 7.89 & 100.00 & 9.21 & 106.39 & 14.52 & $63.10^{*}, \&$ & 9.28 \\
\hline $\mathrm{FC}$ & 100.00 & 6.85 & 85.07 & 6.97 & 94.47 & 3.51 & 100.00 & 7.42 & 112.73 & 8.24 & $87.08^{\&}$ & 5,25 \\
\hline lob 1-3 & - & - & - & - & - & - & - & - & - & - & - & - \\
\hline lob 4-7 & 100.00 & 9.03 & 125.57 & 27.43 & $61.94 *, \&$ & 7.47 & 100.00 & 10.15 & 102.79 & 10.46 & 112.80 & 13.15 \\
\hline \multirow[t]{2}{*}{ lob $8-10$} & 100.00 & 15.67 & $45.06^{*}$ & 5.68 & $115.43^{\#}$ & 24.50 & - & - & - & - & - & - \\
\hline & \multicolumn{12}{|c|}{ 3-MT/DA } \\
\hline $\mathrm{CP}$ & 100.00 & 5.12 & 96.14 & 4.50 & 86.21 & 3.99 & 100.00 & 5.62 & 101.93 & 7.04 & 105.66 & 9.16 \\
\hline SN & 100.00 & 19.97 & 97.35 & 23.56 & 80.95 & 22.87 & 100.00 & 4.83 & 113.38 & 11.95 & 100.74 & 3.95 \\
\hline $\mathrm{FC}$ & - & - & - & - & - & - & - & - & - & - & - & - \\
\hline lob $1-3$ & - & - & - & - & - & - & - & - & - & - & - & - \\
\hline lob 4-7 & 100.00 & 17.19 & $56.29^{\#}$ & 20.68 & $448.74 *$ & 11.77 & 100.00 & 12.43 & 128.15 & 27.45 & 122.20 & 43.98 \\
\hline \multirow[t]{2}{*}{ lob $8-10$} & - & - & - & - & - & - & - & - & - & - & - & - \\
\hline & \multicolumn{12}{|c|}{ 5-HIAA/5-HT } \\
\hline $\mathrm{CP}$ & 100.00 & 2.22 & 98.62 & 2.29 & 106.32 & 4.90 & 100.00 & 4.91 & 113.46 & 6.59 & 108.21 & 10.15 \\
\hline SN & 100.00 & 3.30 & 112.06 & 5.67 & 110.50 & 6.79 & 100.00 & 5.70 & 104.09 & 3.53 & 103.41 & 5.56 \\
\hline $\mathrm{FC}$ & 100.00 & 4.47 & 97.00 & 2.88 & 100.16 & 4.10 & 100.00 & 6.85 & 108.39 & 6.71 & 120.61 & 12.76 \\
\hline lob $1-3$ & 100.00 & 10.24 & 138.27 & 20.62 & 126.90 & 23.09 & 100.00 & 8.82 & 100.14 & 6.50 & 116.19 & 13.37 \\
\hline lob 4-7 & 100.00 & 9.71 & 81.75 & 9.60 & 86.25 & 8.20 & 100.00 & 4.62 & 98.99 & 6.50 & $76.37^{*}, \&$ & 9.35 \\
\hline lob $8-10$ & 100.00 & 6.55 & 89.51 & 5.72 & $128.56^{*}, \&$ & 10.40 & 100.00 & 12.91 & 124.96 & 15.52 & 111.76 & 8.57 \\
\hline
\end{tabular}

One-way ANOVA and LSD post hoc test

$D E S$ desipramine, $C P$ caudate-putamen, $F C$ frontal cortex, $S N$ substantia nigra, lob 1-3 lobules 1-3, lob 4-7 lobules 4-7, lob 8-10 lobules 8-10 of the cerebellum

${ }^{*} p<0.05$ vs. respective sham, ${ }^{\#} 0.05<p<0.1$ vs. respective sham, ${ }^{\&} p<0.05$ vs. 6 -OHDA

lobules 4-7 (by 18\%) and 8-10 (by 19\%) but raised it in lobules $1-3$ (by $100 \%$; Fig. 7). Moreover, the above injections attenuated the DOPAC level and the DOPAC/ dopamine, 3-MT/dopamine and HVA/dopamine ratios in lobules 4-7 (Fig. 6, Table 2). In contrast, the levels of dopamine in lobules 1-3, DOPAC, HVA and HVA/ dopamine ratio in lobules $8-10$ and/or 1-3 were increased significantly (Fig. 6, Table 2). The above injection decreased additionally the 5-HIAA level and tended to lower that of 5-HT in the lobules 4-7 of the cerebellum
(Fig. 7) but elevated the 5-HIAA/5-HT ratio in the lobules 8-10 (Table 2).

Caudate-Putamen, Substantia Nigra, Frontal Cortex 6OHDA in a dose of $8 \mu \mathrm{g} / 0.5 \mu \mathrm{l}$ injected bilaterally into the lobules $9-10,30 \mathrm{~min}$ after desipramine $(15 \mathrm{mg} / \mathrm{kg}$ ip) reduced the level of noradrenaline in the substantia nigra (Fig. 7). No other alterations in neurotransmitters and their metabolites were observed either in the above structure, in the caudate-putamen, or in the frontal cortex. 


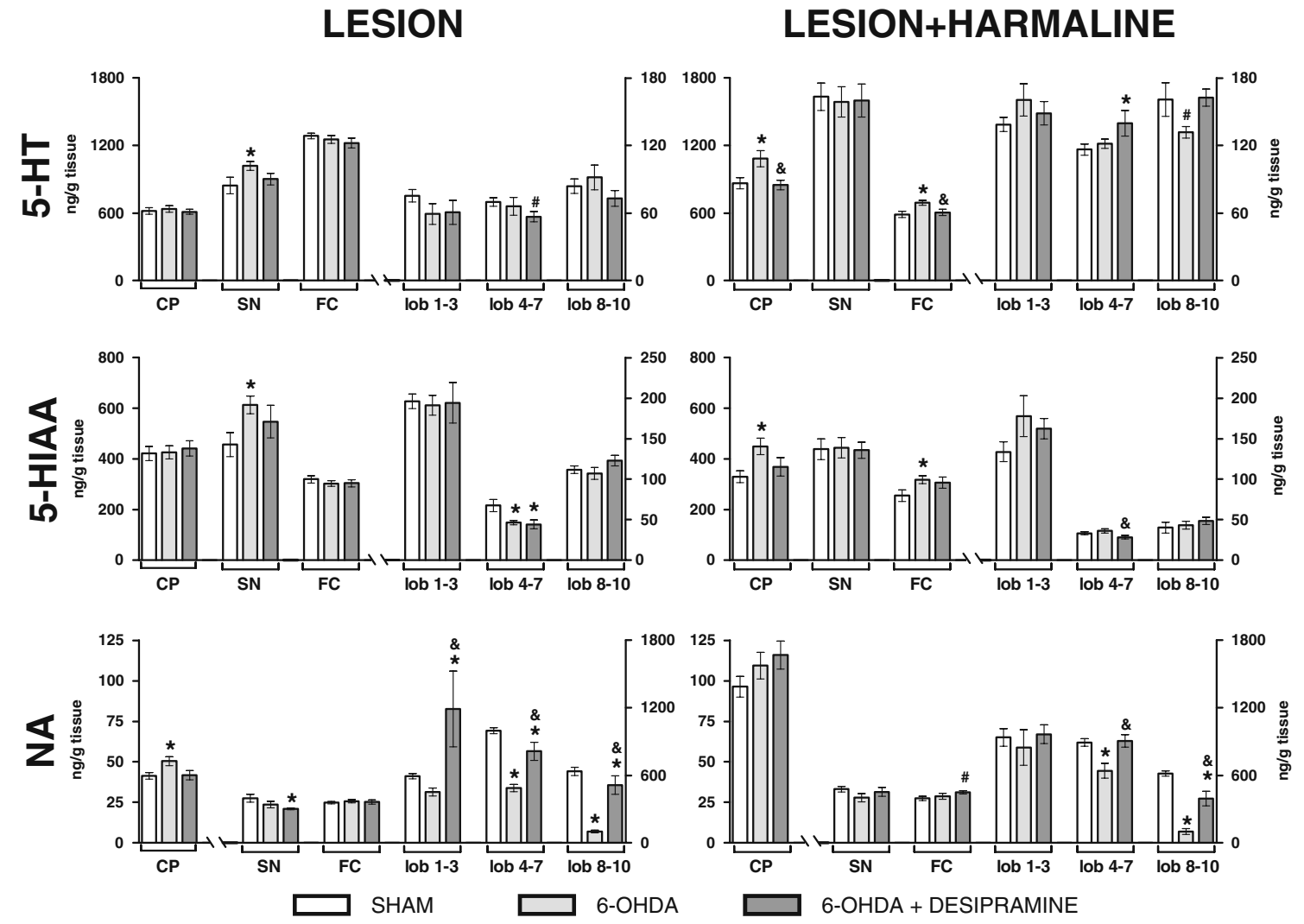

Fig. 7 An influence of lesions of cerebellar catecholaminergic innervations on the levels of serotonin (5-HT), 5-HIAA and noradrenaline (NA) in different brain structures in untreated (left panel) or harmaline-treated $(7.5 \mathrm{mg} / \mathrm{kg}$, right panel) rats. For further explanations, see Fig. 6

An Influence of Lesions of Catecholaminergic Innervations of the Cerebellum on the Harmaline-Induced Alterations of Dopamine, Noradrenaline, Serotonin, and Their Metabolites in Brain Structures

\section{Intracerebellar Injections of 6-OHDA}

All biochemical measurements were carried out in rats treated with $7.5 \mathrm{mg} / \mathrm{kg}$ of harmaline $120 \mathrm{~min}$ after its ip injections.

Cerebellum 6-OHDA injected in a dose of $8 \mu \mathrm{g} / 0.5 \mu \mathrm{l}$ bilaterally into the lobules 9-10 dramatically decreased the noradrenaline level in lobules $8-10$ (by $84 \%$ ) and to a lesser extent in lobules 4-7 (by 28\%) but did not influence the level of this neurotransmitter in lobules 1-3 after harmaline (Fig. 7). The above lesion did not influence the dopamine level in the cerebellum, but increased the DOPAC level in lobules 4-7 (Fig. 6).

Caudate-Putamen, Substantia Nigra, Frontal Cortex 6OHDA was injected in a dose of $8 \mu \mathrm{g} / 0.5 \mu \mathrm{l}$ bilaterally into the lobules 9-10 increased the serotonin and 5-HIAA levels in the caudate-putamen and frontal cortex in the harmalinetreated rats (Fig. 7). In the substantia nigra, only the
DOPAC/dopamine ratio was reduced in the harmalinetreated rats (Table 2).

\section{Intracerebellar Injections of 6-OHDA Together} with Desipramine

All biochemical measurements were carried out in rats treated with $7.5 \mathrm{mg} / \mathrm{kg}$ of harmaline $120 \mathrm{~min}$ after its ip injections.

Cerebellum 6-OHDA in a dose of $8 \mu \mathrm{g} / 0.5 \mu \mathrm{l}$ injected bilaterally into the lobules 9-10, $30 \mathrm{~min}$ after desipramine (15 $\mathrm{mg} / \mathrm{kg}$ ip), decreased the noradrenaline level by ca. $36 \%$ in lobules $8-10$ but did not change it in any other cerebellar regions in rats treated with harmaline (Fig. 7). In contrast, this lesion increased the DOPAC level and DOPAC/dopamine ratio in lobules 8-10 (Table 2, Fig. 6). The serotonin level was increased and 5-HIAA/serotonin ratio decreased in lobules 4-7 (Fig. 7). In contrast, the level of serotonin was not changed in lobules $1-3$ and $8-10$, but the 5-HIAA/ serotonin ratio was increased in the latter region (Table 1).

Caudate-Putamen, Substantia Nigra, Frontal Cortex 6OHDA injected in a dose of $8 \mu \mathrm{g} / 0.5 \mu \mathrm{l}$ bilaterally into the 
lobules 9-10 $30 \mathrm{~min}$ after desipramine (15 $\mathrm{mg} / \mathrm{kg}$ ip) increased the DOPAC level in the substantia nigra in rats treated with harmaline (Fig. 6). In the latter structure, the HVA level was not significantly changed, but the HVA/ dopamine ratio was diminished (Table 2, Fig. 6).

\section{Discussion}

The most important result of the present study is the finding that 6-OHDA injected bilaterally into the cerebellum enhanced the harmaline-induced tremor of forelimbs. The cerebellum receives two catecholaminergic projections: a weak dopaminergic pathway arising from the region comprising the ventral tegmental area and/or substantia nigra, and an intensive noradrenergic projection from the pontine locus coeruleus [10-14]. It was presumed that 6OHDA injected alone would destroy terminals of both catecholaminergic inputs to the cerebellum. Examination of the lesion extent was carried out biochemically. This analysis revealed that 6-OHDA dramatically reduced the noradrenaline level in the region of cannulae placement (lobules 8-10) and to a lesser extent in the neighboring cerebellar region (lobules 4-7) in animals. Only the most rostral part of the cerebellum (lobules 1-3) was spared. In contrast, however, a lesion of dopaminergic system seemed to be very small and compensated for. Only dopamine turnover measured by the ratios for its extracellular metabolite 3-MT/dopamine (cf. [34]) and HVA/dopamine was reduced in some regions of the cerebellum, but the level of this neurotransmitter was not decreased but even increased.

In contrast to 6-OHDA administered alone, this toxin injected together with desipramine, in order to protect noradrenergic terminals, did not influence the harmalineinduced forelimb tremor. Although such treatment did not decrease the level of dopamine in the cerebellum in rats, it lowered dramatically the DOPAC level and dopamine turnover (measured by all metabolites/dopamine ratios) in the lobules 4-7. In contrast, the levels of dopamine, its metabolites (DOPAC, HVA) and turnover (measured by the ratio for its final metabolite-HVA/dopamine) were increased in neighboring regions of the cerebellum. The above biochemical data seem to suggest that some dopaminergic terminals in the region of lobules 4-7 were destroyed by the toxin that triggered a compensatory response in other parts of the cerebellum. The affected region was not located close to the cannulae tips (lobules 810), which seems to suggest that while noradrenergic terminals were protected by desipramine, the 6-OHDA solution further diffused across the cerebellum after injection. The dopaminergic innervation in the cerebellum is rather low [10-13] and, therefore, only a small amount of the toxin could be taken up by these terminals at the site of injection. However, such treatment appeared to be not fully selective because small decreases in noradrenaline levels in lobules 4-7 and 8-10, as well as serotonin and 5-HIAA in lobules 4-7 were noted. These alterations seemed to be also compensated for which was visible as an increase in the noradrenaline level and serotonin turnover in neighboring cerebellar regions.

Summing up, the above comparison of biochemical effects of treatments with 6-OHDA alone and together with desipramine strongly indicates that the lesion of noradrenergic (but not dopaminergic) cerebellar terminals was responsible for enhancement of the harmaline-induced forelimb tremor and implies for the first time an inhibitory influence of the cerebellar noradrenergic innervation on this symptom. These results are in a good agreement with the previous study of Yamazaki et al. [25] who found that a lesion of the locus coeruleus enhanced the harmalineinduced tremor, whereas stimulation of this structure or injections of L-threo-DOPS (a noradrenaline precursor [35]) which increased the level of noradrenaline in several brain structures, including the cerebellum, decreased this symptom in rats.

Harmaline is a highly selective, reversible inhibitor of MAO-A (an enzyme preferentially deaminating dopamine, noradrenaline and serotonin [36]), which blocks this enzyme's isoform in nanomolar concentrations [37]. In accordance with this mechanism, harmaline administered in the present study reduced tissue levels of DOPAC, HVA, 5HIAA, and increased the level of serotonin and noradrenaline in most of the structures examined, including cerebellum. Although in vivo microdialysis studies after harmaline administration are lacking, it may be expected that this compound increases extracellular levels of monoamines in the above structures. This suggestion is based on previous studies which showed that other MAO-A inhibitors (including another $\beta$-carboline derivative-harman [38]), increased extracellular levels of dopamine [37, 3941], noradrenaline [37, 39], and serotonin [39, 42] in different brain structures. In an agreement with the above results, the present study showed elevated levels of the extracellular dopamine metabolite-3-MT (cf. [34]) in the caudate-putamen, substantia nigra, and frontal cortex after harmaline administration. Therefore, in the light of the present findings showing that a lesion of cerebellar noradrenergic innervation increases the harmaline-induced tremor, the question arises what is the contribution of the enhanced noradrenergic transmission evoked by this compound to this symptom. However, we found additionally that the above lesion induced by $6-O H D A$ administered alone strongly lowered the noradrenaline level in lobules 8 10 and to a lesser extent in lobules 4-7 in the harmaline- 
treated animals. When 6-OHDA was administered together with desipramine, some decline in noradrenaline level in the harmaline-treated animals was also observed in lobules $8-10$; however, it seemed to be too low to influence the tremor evoked by this compound. These results seem to suggest that the increased noradrenergic transmission induced by harmaline in the cerebellum may counteract the tremor induced by this compound. This view is supported also by the present results demonstrating that increases in the noradrenaline level in the cerebellum induced by this compound in naïve rats showed a Ushaped dose dependency. It appeared that the elevation of the cerebellar level of this neurotransmitter induced by the higher dose of this drug $(15 \mathrm{mg} / \mathrm{kg})$, which induced extremely strong tremor, was much weaker and shorter than that evoked by the lower dose $(7.5 \mathrm{mg} / \mathrm{kg})$ after which this symptom was only moderate.

Increased synchronous oscillatory activity of the neurons of the inferior olive and olivo-cerebellar climbing fibers, which induces release of glutamate in the cerebellum and rhythmic firing pattern of complex spikes of the Purkinje cells, has been suggested to be the primary cause of the harmaline-induced tremor $[18,22,23]$. Oscillatory activity of the inferior olive neurons has been found to be blocked by noradrenaline [43]; however, cerebellar mechanisms by which this neurotransmitter inhibits tremor cannot be easily specified. Electrophysiological studies indicated that noradrenaline suppressed spontaneous firing of Purkinje cells and induced their hyperpolarization (for ref. see [44]). However, it also modulated synaptic actions increasing both the excitatory (induced by activation of climbing fibers) and inhibitory (evoked by stimulation of spontaneous firing of GABA-ergic interneurons - basket cells) influences on Purkinje cells [44-46]. Therefore, it seems that the role of cerebellar noradrenaline is mainly modulatory and it serves to keep homeostasis in this structure. The lack of this neurotransmitter increased susceptibility of this structure to pathological oscillations.

The lesion of noradrenergic terminals in the cerebellum induced compensatory alterations also in distant structures; namely, it increased the noradrenaline level in the caudateputamen and the serotonin and 5-HIAA levels in the substantia nigra. Moreover, this lesion enhanced serotonin and 5-HIAA levels in the caudate-putamen and frontal cortex in rats treated with harmaline. The latter result seems to indicate a contribution of the increased serotonergic transmission to the harmaline-induced tremor. Such relationship has already been strongly suggested by others. It has been found that the inhibition of serotonin synthesis by systemic administration of $p$-chlorophenylalanine (PCPAa tryptophan hydroxylase inhibitor [26]), or a lesion of serotonergic brain system induced by intraventricular 5,6or 5,7-dihydroxytryptamine injections [24], decreased this symptom, whereas serotonin reuptake inhibitors (selective - citalopram, or non-selective-imipramine) enhanced it $[47,48]$. A number of studies have suggested that activation of serotonergic system at the level of the inferior olive and the cerebellum was responsible for the aforementioned enhancement of the harmaline-induced tremor. Similar to the present study, harmaline reportedly increased the serotonin level in the cerebellum and inferior olive [26, $47,48]$, while PCPA or serotonergic toxins decreased it [26], and reversed the harmaline-induced activation of climbing fibers [24]. Moreover, stimulation of 5-HT2A receptors in the inferior olive increased an average firing rate, rhythmicity, and synchronicity of complex spikes in Purkinje cells [49]. Our present results extend former studies and seem to suggest for the first time that the increased serotonergic transmission in the caudate-putamen and frontal cortex may also contribute to the harmalineinduced tremor.

Serotonergic transmission has also been suggested to contribute to the tremor induced by acetylcholinesterase inhibitors: organophosphates [50], physostigmine [51-53], and tacrine [54-56], which has been suggested to result from activation of the striatal cholinergic transmission [54]. A number of findings showed consistently that these compounds enhanced also the level of serotonin, and its turnover or release in several brain structures including the inferior olive, cerebellum, striatum, substantia nigra, cerebral cortex, dorsal raphe nucleus, and others $[50,51,55-$ 58]. Moreover, similar to the harmaline-induced tremor, the tremor induced by acetylcholesterase inhibitors was reduced by inhibition of serotonin synthesis by PCPA or blockade of 5 -HT2A/2C receptors $[55,56]$. All the above data together with those of the present study may suggest that an increased serotonergic transmission in several brain structures, including the basal ganglia and frontal cortex, may be a common mechanism involved in different forms of tremor.

The question arises how the lesion of noradrenergic innervations of the cerebellar cortex modulated serotonergic and noradrenergic transmission in distant structures. Purkinje cells, which are innervated by noradrenergic terminals arising from the locus coeruleus [14], are the main efferent neurons of the cerebellar cortex and extend their projections to the subcortical cerebellar nuclei [59]. These nuclei, in turn, send their fibers to the thalamus and via the latter structure may functionally control the striatum and cerebral cortex $[60,61]$. On the other hand, it could be expected that the intracerebellar injection of a noradrenergic toxin retrogradely destroyed the coeruleo-cerebellar pathway which might induce a compensatory activation of other projections of the locus coeruleus to the striatum, cerebral cortex, and raphe nuclei [62-64] and in this way may interact with serotonergic neurons at the levels of these structures. Precise neuronal 
mechanisms involved in these interactions and their relation to the harmaline-induced tremor may be, however, very complex and needs to be evaluated in the future.

Summing up, the present study shows that degeneration of noradrenergic terminals in the cerebellar cortex enhances the harmaline-induced tremor and modulates noradrenergic and serotonergic transmissions in the basal ganglia and frontal cortex. The role of these alterations in different forms of tremor in humans has to be established in the future.

Acknowledgments The study was supported by the grant of the Ministry of Science and Higher Education nr NN401 570638, and partly by Statutory Funds of the Department of NeuroPsychopharmacology, Institute of Pharmacology, Polish Academy of Sciences, Kraków, Poland.

The excellent technical assistance of Mrs. Urszula Mikołajun is gratefully acknowledged.

Open Access This article is distributed under the terms of the Creative Commons Attribution Noncommercial License which permits any noncommercial use, distribution, and reproduction in any medium, provided the original author(s) and source are credited.

\section{References}

1. DeLong MR. Possible involvement of central pacemakers in clinical disorders of movement. Fed Proc. 1978;37:2171-5.

2. Deiber M-P, Pollak P, Passingham R, Landais P, Gervason C, Cinotti L, et al. Thalamic stimulation and suppression of parkinsonian tremor. Brain. 1993;116:267-79.

3. Deuschl G, Raethjen J, Baron R, Lindemann M, Wilms H, Krack P. The pathophysiology of parkinsonian tremor: a review. J Neurol. 2000;247 Suppl 5:v/33-48.

4. Timmermann L, Gross J, Dirks M, Volkmann J, Freund HJ, Schnitzler A. The cerebellar oscillatory network of parkinsonian resting tremor. Brain. 2003;126:199-212.

5. Fukuda M, Barnes A, Simon ES, Holmes A, Dhavan V, Giladi $\mathrm{N}$, et al. Thalamic stimulation for parkinsonian tremor: correlation between regional cerebral blood flow and physiological tremor characteristics. Neuroimage. 2004;21:608-15.

6. Rolland A-S, Herrero M-T, Garcia-Martinez V, Ruberg M, Hirsch EC, Francois C. Metabolic activity of cerebellar and basal ganglia-thalamic neurons is reduced in parkinsonism. Brain. 2007;130:265-75.

7. Yang J, Sadler TR, Givrad TK, Maarek J-M, Holschneider DP. Changes in brain functional activation during resting and locomotor states after unilateral damage in rats. Neuroimage. 2007;36:755-73.

8. Yu H, Sternad D, Corcos DM, Vaillancourt DE. Role of hyperactive cerebellum and motor cortex in Parkinson's disease. Neuroimage. 2007;35:222-33.

9. Benninger DH, Thees S, Kollias SS, Bassetti CL, Waldvogel D. Morphological differences in Parkinson's disease with and without rest tremor. J Neurol. 2009;256:256-63.

10. Kizer JS, Palkovits M, Brownstein MJ. The projections of the A8, A9 and A10 dopaminergic cell bodies: evidence for a nigralhypothalamic-median eminence dopaminergic pathway. Brain Res. 1976;108:363-70.
11. Panagopoulos NT, Panagopoulos GC, Matsokis NA. Dopaminergic innervation and binding in the rat cerebellum. Neurosci Lett. 1991;130:208-12.

12. Ikai Y, Takada M, Shinonaga Y, Mizuno N. Dopaminergic and non-dopaminergic neurons in the ventral tegmental area of the rat project, respectively, to the cerebellar cortex and deep cerebellar nuclei. Neuroscience. 1992;51:719-28.

13. Melchitzky DS, Lewis DA. Tyrosine hydroxylase- and dopamine transporter-immunoreactivity axons in the primate cerebellum. Evidence for a lobular- and laminar-specific dopamine innervation. Neuropsychopharmacology. 2000;22:466-72.

14. Samuels ER, Szabadi E. Functional neuroanatomy of the noradrenergic locus coeruleus: its roles in the regulation of arousal and autonomic function part I; principles of functional organization. Curr Neuropharmacol. 2008;6:235-53.

15. Braak H, Ghebremedhin E, Rüb U, Bratzke H, Del Tredeci K. Stages in the development of Parkinson's disease-related pathology. Cell Tissue Res. 2004;318(1):121-34.

16. Louis ED, Honig LS, Vonsattel JP, Maraganore DM, Borden S, Moskowitz CB. Essential tremor associated with focal nonnigral Lewy bodies: a clinicopathologic study. Arch Neurol. 2005;62:1004-7.

17. Shill HA, Adler CH, Sabbagh MN, Connor DJ, Caviness JN, Hentz JG, et al. Pathologic findings in prospectively ascertained essential tremor. Neurology. 2008;70:1452-5.

18. Miwa H. Rodent models of tremor. Cerebellum. 2007;6:6672.

19. Milner TE, Cadoret G, Lessard L, Smith AM. EMG analysis of harmaline-induced tremor in normal and three strains of mutant mice with Purkinje cell degeneration and the role of the inferior olive. J Neurophysiol. 1995;73:2568-77.

20. Wang G, Fowler SC. Concurrent quantification of tremor and depression of locomotor activity induced in rats by harmaline and physostigmine. Psychopharmacology. 2001;158:273-80.

21. Kolasiewicz W, Kuter K, Wardas J, Ossowska K. Role of the metabotropic receptor subtype 1 in the harmaline-induced tremor in rats. J Neural Transm. 2009;116:1059-63.

22. Beitz AJ, Saxon D. Harmaline-induced climbing fiber activation causes amino acid and peptide release in the rodent cerebellar cortex and a unique temporal pattern of Fos expression in the olivo-cerebellar pathway. J Neurocytol. 2004;33:49-74.

23. Paterson NE, Malekiani SA, Foreman MM, Olivier B, Hanania T. Pharmacological characterization of harmaline-induced tremor activity in mice. Eur J Pharmacol. 2009;616:73-80.

24. Sjölund B, Björklund A, Wiklund J. The indoleaminergic innervations of the inferior olive. 2. Relation to harmaline induced tremor. Brain Res. 1977;131:23-7.

25. Yamazaki M, Tanaka C, Takaori S. Significance of central noradrenergic system on harmaline-induced tremor. Pharmacol Biochem Behav. 1979;10:421-7.

26. Mehta H, Saravanan KS, Mohanakumar KP. Serotonin synthesis inhibition in olivo-cerebellar system attenuates harmaline-induced tremor in Swiss albino mice. Behav Brain Res. 2003;145:31-6.

27. Batini C, Buisseret-Delmans C, Conrath-Verrier M. Harmalineinduced tremor and cerebral activities: labeling with 14C-2deoxyglucose in the rat. CR Acad Sci Hebd Seances Acad Sci D. 1978;287:527-30.

28. Batini C, Buisseret-Delmans C, Conrath-Verrier M. Harmalineinduced tremor. I. Regional metabolic activity as revealed by [14C]2-deoxyglucose in cat. Exp Brain Res. 1981;42:371-82.

29. Miwa H, Nishi K, Fuwa T, Mizuno Y. Differential expression of cFos following administration of two tremorgenic agents: harmaline and oxotremorine. NeuroReport. 2000;11:2385-90.

30. Poirier LJ, Sourkes TL, Bouvier G, Boucher R, Carabin S. Striatal amines experimental tremor and the effect of harmaline in the monkey. Brain. 1966;89:37-52. 
31. Paxinos G, Watson C. The rat brain. 4th ed. New York: Academic Press; 1998.

32. Ossowska K, Wardas J, Śmiałowska M, Kuter K, Lenda T, Wierońska JM, et al. A slowly developing dysfunction of dopaminergic nigrostriatal neurons induced by long-term paraquat administration in rats: an animal model of preclinical stages of Parkinson's disease. Eur J Neurosci. 2005;22:1294-304.

33. Pietraszek M, Michaluk J, Romańska I, Wąsik A, Gołembiowska K, Antkiewicz-Michaluk L. 1-Methyl-1, 2, 3, 4-tetrahydroisoquinoline antagonizes a rise in brain dopamine metabolism, glutamate release in frontal cortex and locomotor hyperactivity produced by MK-801 but not the disruptions of prepulse inhibition, and impairment of working memory in rat. Neurotox Res. 2009;16:390-407.

34. Männistö PT, Kaakola S. Catechol-O-methyltrasferase (COMT): biochemistry, molecular biology, pharmacology, and clinical efficacy of the new selective COMT inhibitors. Pharmacol Rev. 1999;51:593-628.

35. Karai N, Kato T, Katsuyama M, Nakamura M, Katsube J. Effect of L-threo-3, 4-dihydroxyphenylserine (L-threo-DOPS) on brain and serum MHPG levels in mice: evidence for NE formation in CNS. Life Sci. 1987;40:2261-8.

36. Johnston JP. Some observations upon a new inhibitor of monoamine oxidase in brain tissue. Biochem Pharmacol. 1968;17:1286-97.

37. Curet O, Damoiseau-Ovens G, Sauvage C, Sontag N, Avenet H, Depoortere $\mathrm{H}$, et al. Preclinical profile of befloxatone, a new reversible MAO-A inhibitor. J Affect Disord. 1998;51:287-303.

38. Rommelspacher H, May T, Salewski B. Harman (1-methyl- $\beta$ carboline) is a natural inhibitor of monoamine oxidase type $\mathrm{A}$ in rats. Eur J Pharmacol. 1994;252:51-9.

39. Curet O, Damoiseau G, Labaune JP, Rovel V, Jarrau FX. Effects of befloxatone, a new potent reversible MAO-A inhibitor, on cortex and striatum monoamines in freely moving rats. J Neural Transm Suppl. 1994;41:349-55.

40. Baum SS, Hill R, Rommelspacher H. Harman-induced changes of extracellular concentrations of neurotransmitters in the nucleus accumbens of rats. Eur J Pharmacol. 1996;314:75-82.

41. Colzi A, D’Agostini F, Cesura AM, Borroni E, Da Prada M. Monoamine oxidase-A inhibitors and dopamine metabolism in rat caudatus: evidence that an increased cytosolic level of dopamine displaces reversible monoamine oxidase-A inhibitors in vivo. $\mathrm{J}$ Pharmacol Exp Ther. 1993;265:103-11.

42. Adell A, Biggs TA, Myers RD. Action of harman (1-methyl- $\beta$ carboline) on the brain: body temperature and in vivo efflux of 5-HT from hippocampus of the rat. Neuropharmacology. 1996;35:1101-7.

43. Llinás R, Yarom Y. Oscillatory properties of guinea-pig inferior olivary neurons and their pharmacological modulation: an in vitro study. J Physiol. 1986;376:163-82.

44. Woodward DJ, Moises HC, Waterhouse BD, Yeh HH, Cheun JE. The cerebellar norepinephrine system: inhibition, modulation, and gating. Prog Brain Res. 1991;88:331-41.

45. Saitow F, Satake S, Yamada J, Konishi S. $\beta$-adrenergic receptormediated presynaptic facilitation of inhibitory GABAergic transmission at cerebellar interneuron-Purkinje cell synapses. J Neurophysiol. 2000;84:2016-25.

46. Hirono M, Obata K. $\alpha$-Adrenoceptive dual modulation of inhibitory GABAergic inputs to Purkinje cells in the mouse cerebellum. J Neurophysiol. 2006;95:700-8.

47. Arshaduddin M, Al Kadasah S, Biary N, Al Deeb S, Al Moutaery K, Tariq M. Citalopram, a selective serotonin reuptake inhibitor augments harmaline-induced tremor in rats. Behav Brain Res. 2004; $153: 15-20$

48. Arshaduddin M, Kadasah S, Al Deeb S, Al Moutaery K, Tariq M. Exacerbation of harmaline-induced tremor by impramine. Pharmacol Biochem Behav. 2005;81:9-14.

49. Sugihara I, Lang EJ, Llinás R. Serotonin modulation of inferior olivary oscillations and synchronicity: a multiple-electrode study in the rat cerebellum. Eur J Neurosci. 1995;7:521-34.

50. Fernando JC, Hoskins BH, Ho IK. A striatal serotonergic involvement in the behavioral effects of anticholinesterase organophosphates. Eur J Pharmacol. 1984;98:129-32.

51. Mohanakumar KP, Mitra N, Ganguly DK. Tremorogenesis by physostigmine is unrelated to acetylcholinesterase inhibition: evidence for serotonergic involvement. Neurosci Lett. 1990;120:91-3.

52. Sarkar S, Thomas B, Muralikrishnan D, Mohanakumar KP. Effects of serotonergic drugs on tremor induced by physostigmine in rats. Behav Brain Res. 2000;109:187-93.

53. Mehta H, Thomas B, Mohanakumar KP. Effects of pchlorophenylalanine on striatal acetylcholinesterase activity and on biogenic amin levels in nuclei raphe and caudate-putamen during physostigmine-induced tremor in rats. Neurosci Lett. 2001;299:105-8.

54. Salamone JD, Mayorga AJ, Trevitt JT, Cousins MS, Conlan A, Nawab A. Tremulous jaw movements in rats: a model of parkinsonian tremor. Prog Neurobiol. 1998;56:591-611.

55. Carlson BB, Wisniecki A, Salamone JD. Local injections of the 5hydroxytryptamine antagonist mianserin into substantia nigra pars reticulata block tremulous jaw movements in rats; studies with a putative model of Parkinsonian tremor. Psychopharmacology. 2003;165:229-37.

56. Mehta H, Haobam R, Usha R, Mohanakumar KP. Evidence for the involvement of central serotonergic mechanisms in cholinergic tremor induced by tacrine in Balb/c mice. Behav Brain Res. 2005;163:227-36.

57. Robinson TN, De Souza RJ, Cross AJ, Green AR. The mechanism of tetrahydroaminoacridine-evoked release of endogenous 5-hydroxytryptamine and dopamine from rat brain tissue prisms. Br J Pharmacol. 1989;98:1127-36.

58. Tani Y, Saito K, Tsuneyoshi A, Imoto M, Ohno T. Nicotinic acetylcholine receptor (nACh-R) agonist-induced changes in brain monoamine turnover in mice. Psychopharmacology. 1997;129:22532.

59. Voogd J, Glickstein M. The anatomy of the cerebellum. Trends Cogn Sci. 1998;2:307-13.

60. Ichinohe N, Mori F, Shoumura K. A di-synaptic projection from the lateral cerebellar nucleus to the laterodorsal part of the striatum via the central lateral nucleus of the thalamus in the rat. Brain Res. 2000;880:191-7.

61. Hoshi E, Tremblay L, Féger J, Carras PL, Strick PL. The cerebellum communicates with the basal ganglia. Nat Neurosci. 2005;8:1491-3.

62. Mason ST, Fibiger HC. Regional topography within noradrenergic locus coeruleus as revealed by retrograde transport of horseradish peroxidase. J Comp Neurol. 1979;187:703-24.

63. Baraban JM, Aghajanian GK. Suppression of firing activity of 5HT neurons in the dorsal raphe by alpha-adrenoceptor antagonists. Neuropharmacology. 1980;19:355-63.

64. Peyron C, Luppi PH, Fort P, Rampon C, Jouvet M. Lower brainstem catecholamine afferents to the rat dorsal raphe nucleus. J Comp Neurol. 1996;364:402-13. 